\title{
Dimensional Stability and Characteristics of Modified Young Teak (Tectona grandis L.f.) Wood with PEG-1000
}

\author{
Tomy Listyanto, Muhammad Navis Rofii, Keisuke Ando, and Nobuaki Hattori
}

\begin{abstract}
The aim of this study was to investigate the effect of wood modification with polyethylene glycol (PEG)-1000 at five concentrations to improve dimensional stability, drying, machining and finishing characteristics of young teak wood. A total of 12 samples for each treatment was prepared to measure an Anti Shrink Efficiency (ASE), as a parameter of dimensional stability and its drying characteristics. Six samples for each treatment were prepared to evaluate machining and finishing characteristics. PEG-1000 with five concentration levels of $20 \%, 30 \%, 40 \%, 50 \%$ and $60 \%$ were impregnated to modify the samples, except control. Afterward, all samples were kiln dried to gain $12 \%$ moisture content. ASE was determined by comparing shrinkage percentage of treated sample with those of untreated one. Warping and surface checks were measured as drying characteristics and machining test was conducted in accordance to ASTM D1666-2004. After coating with a nitrocellulose system, surface quality were evaluated by conducting cross-cut test (ASTM D3359), coin test, delamination test (SNI 01-5008.2-1999b) and glossyness test (SNI-06-6052-1999a). Result shows that dimensional stability of impregnated samples with concentration of 30 60\% was successfully improved, with ASE of 52 62\%. All treated samples demonstrated good drying characteristics and defect-free areas which were more than $90 \%$ under machining test. Surface evaluation by delamination test, glossyness test, and coin test indicated that all impregnated samples were well coated by a nitrocellulose system. However, only impregnated samples in concentration of $20 \%$ and $30 \%$ showed a good result in cross-cut test. Impregnation with PEG-1000 in concentration of $30 \%$ is recommended to modify young teak wood.
\end{abstract}

Keywords: teak, PEG-1000, dimensional stability, drying, machining, finishing.

\section{Introduction}

Wood is having high ability on water absorption and desorption, when exposed to environmental condition due to the existence of hydroxyl group in polymer (Fadl and Basta 2005). Moisture loss may cause dimensional distortion, which is one of the main problems in wood utilisation. Dimensional stability becomes the main concern for Indonesian teak wood properties. Teak (Tectona grandis L.f.) wood is one the most valuable commercial species in Indonesia.

Teak wood is mostly manufactured for luxury products of furniture, carving and decorative components of building due to its strength, durability and aesthetic qualities (Pandey and Brown 2000). Those properties generally present in the mature teak (60-years-old or more). However, due to massive exploitation in the last two decades, supply of old teak from the well-managed forest, has been decreasing and has been partly replaced by timber originated from private or community forest. These teak is generally harvested in a shorter rotation, which is commonly 20 yearsold or less. However, This type of lumber shows high portion of juvenile tissues (Hadikusumo 2001), which exhibit several minor characteristics such as lower in dimensional stability, density and strength properties. Low dimensional stability cause checking and warping and may affect on the failure during finishing process (Williams 1999). Therefore, it is necessary to improve its dimensional stability and its performance to achieve higher quality products.

Various treatments have been investigated to improve dimensional stability and performance of low grade timber, such as application of heat and pressure, impregnation of chemical reagents, exposure to radiation and plasma treatment (Stam 1959; Hillis 1984; Sangkul 1998; Ibach 1999; Avramidis et al. 2011). Impregnation, which also called bulking process, is aimed to deposit some chemicals within a swollen cell and replacing some water thus preventing shrinkage and formation of cracks during drying (Walker 2006). Polyethylene glycol (PEG) is one of the chemical reagents that has been used to stabilize wood dimension (Stam 1959; Kollmann et al. 1975; Wallstrom and Lindberg 1995; Walker 2006). PEG-1000, which is a chemical reagent with an average molecular weight of 1000 , is non-toxic, non-corrosive, odourless, colourless, and stable at very high fire point (Mitchell and Wahlgren 1959). Impregnation process is selected because PEG-1000 treatment is based on diffusion (Schneider 1994; Ibach 1999). Currently, there is no available study on application of PEG-1000 in young teak wood, especially in Indonesia. Therefore, it is important to investigate an application of PEG-1000 to improve dimensional stability of young teak wood.

To evaluate the effects of PEG-1000 on the next step of manufacture process, investigation on machining and finishing characteristics of treated lumber is also necessary. 
Machining characteristics refer to the behaviour of wood when subjected to the standard operation of wood working such as planing, sanding, shaping, turning, drilling and mortising (Koch 1964). In furniture production, the smoothness and the ability in which timber could be worked by those wood working machines are essential (Davis 1962). Finishing is applied to protect and to decorate timber to achieve desired surface appearance (Panshin and de Zeeuw 1980). Surface texture of timber is one of the factors that influence the finishing process (Richter et al. 1995; Williams 1999). Therefore, lack of information related to machining and finishing properties may cause difficulties to produce high quality timber products. The aim of this research was to investigate the effect of impregnation of PEG-1000 with five concentrations on dimensional stability, machining and finishing characteristics of teak wood, which was harvested from the private forest at 15 years-old.

\section{Materials and Methods}

\section{Materials}

Twelve green teak (Tectona grandis L.f.) logs with length of $600 \mathrm{~mm}$, which were cut from 15-years-old trees, were used in this experiment. Each log was sawn to obtain boards with thickness of $30 \mathrm{~mm}$ (Fig. 1a). To measure dimensional stability, sample with a dimension of $25 \mathrm{~mm}$ (radial) by $25 \mathrm{~mm}$ (tangential) and $100 \mathrm{~mm}$ (longitudinal) was cut from a board at the central part of the logs (Fig. 1b). Twelve replicates were prepared for each concentration of PEG-1000 and control.

For observing drying characteristics, boards with dimension of $120 \mathrm{~mm}$ [width (W)] x $25 \mathrm{~mm}$ [thickness (T)] x
$500 \mathrm{~mm}$ [length (L)] thickness of $30 \mathrm{~mm}$ were sawn (Fig. 1c$\mathrm{d}$ before cutting for machining and finishing samples). Twelve replicates were prepared for each concentration of PEG-1000 and control. Both ends of boards were coated with wax to avoid excessive drying from the ends of boards.

In order to observe machining characteristics, the boards with thickness of $30 \mathrm{~mm}$ were sawn into four types of samples (Fig. 1c). Sample with dimension of $120 \mathrm{~mm}$ (W) $\mathrm{x}$ $25 \mathrm{~mm}$ (T) $\times 250 \mathrm{~mm}(\mathrm{~L})$ was used to measure wood processing properties under planer machine. Two samples with a dimension of $50 \mathrm{~mm}(\mathrm{~W}) \times 25 \mathrm{~mm}(\mathrm{~T}) \times 250 \mathrm{~mm}(\mathrm{~L})$ were prepared for sanding and drilling test. Wood turning test was conducted on the board sample with dimension of $25 \mathrm{~mm}(\mathrm{~W}) \times 25 \mathrm{~mm}(\mathrm{~T}) \times 100 \mathrm{~mm}(\mathrm{~L})$.

Four types of samples of $30 \mathrm{~mm}$ thickness were sawn into $50 \mathrm{~mm}(\mathrm{~W}) \times 25 \mathrm{~mm}$ (T) $\times 250 \mathrm{~mm}$ (L) sample size (Fig. 1d). Samples of $50 \mathrm{~mm}(\mathrm{~W}) \times 25 \mathrm{~mm}(\mathrm{~T}) \times 250 \mathrm{~mm}$ (L) were prepared to conduct cross-cut test, coin test and glossyness test. Delamination test was also conducted using similar samples with the dimension of $50 \mathrm{~mm}(\mathrm{~W}) \times 25 \mathrm{~mm}(\mathrm{~T}) \times$ $100 \mathrm{~mm}$ (L). Six replicates were created for each concentration and control for all parameters in machining and finishing properties.

\section{Methods}

PEG-1000 was dissolved in the warm water to concentration of $20 \%, 30 \%, 40 \%, 50 \%$, and $60 \%$. The impregnation was conducted by dipping the samples in an aqueous solution of PEG-1000 for four days. Then, all samples were kiln dried to reach final $12 \%$ moisture content.

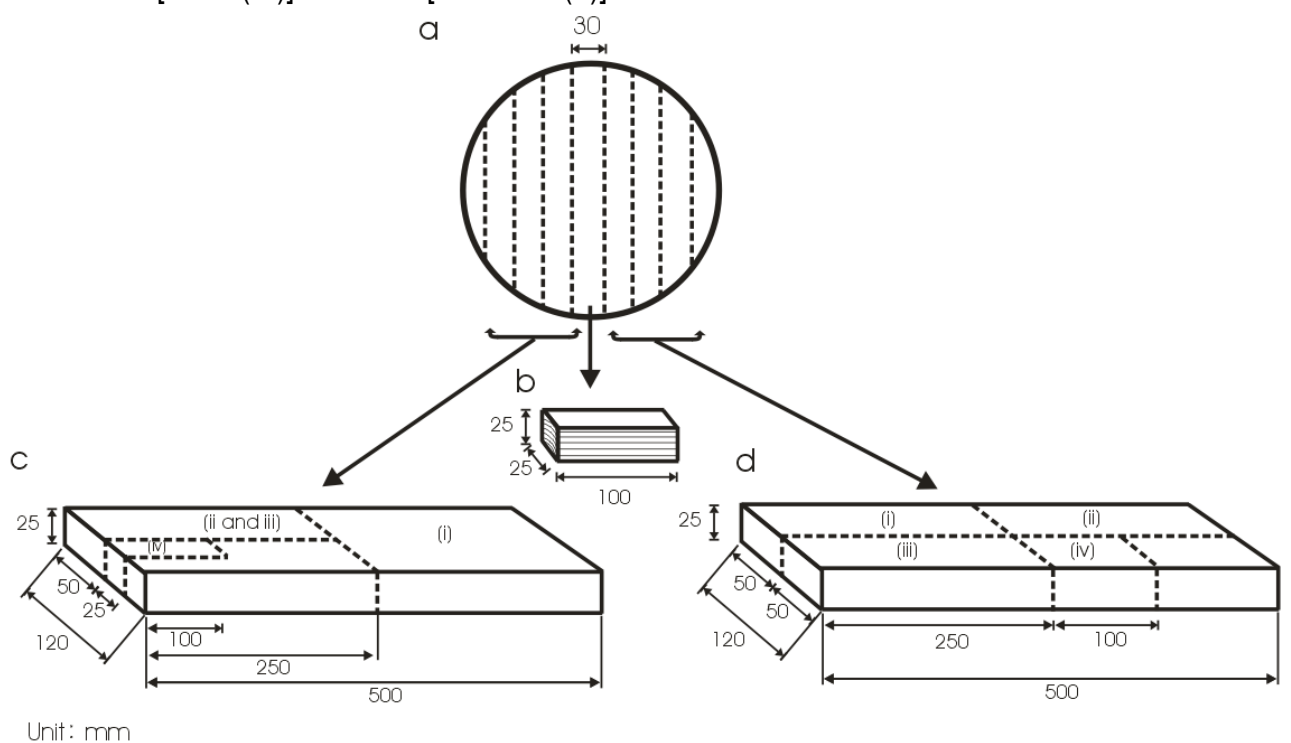

Fig. 1. Sample preparation. a Pattern of log sawing to obtain boards with the thickness of $30 \mathrm{~mm}$, $\mathrm{b}$ Sample preparation for anti-shrink efficiency measurement, c-d Sample for drying characteristics (before cutting for machining and finishing sample). c Sample preparation for machining characteristics, d Samples preparation for finishing characteristics. 
Dimensional stability was determined by measuring Anti Shrink Efficiency (ASE) in both radial and tangential direction. Anti shrink efficiency was calculated by comparing shrinkage of treated sample to the untreated samples.

Samples for drying, machining and finishing test were dried in a dry kiln to obtain final moisture content of $12 \%$. Drying characteristic test such as warping (bowing, crook, cupping), and surface checks were observed accordingly. Warping was assessed by measuring maximum bend per total dimension at the same part. A number and total length of surface check were measured.

Machining test was achieved in accordance to ASTM D1666-87 (ASTM International 2004a), which was modified in terms of dimension of the sample. Raised and torn grain, chips mark and fuzzy grains were observed to identify the defects of the samples after subjecting to planing, sanding, drilling and turning process. The amount of defects was compared to the total surface of the worked area and then expressed as a percentage (\%).

Finishing characteristics was investigated by performing nitrocellulose coating system. After coating with nitrocellulose, surface quality of the sample was evaluated with cross-cut test, coin test, delamination test, and gloss test. Cross-cut test was conducted according to ASTM D3359 (ASTM International 2004b). Multiple cutters consisting of six knives, which was $1 \mathrm{~mm}$ apart, were used to scratch the surface of sample with a lattice pattern. A tape with a width of $25 \mathrm{~mm}$ was applied firmly over the cross-cut area and then removed back immediately. The amount of flaking area lifted at the tape was measured as a percentage of the total area. Coin test was conducted by scratching the surface of coated sample with a coin in an approximately angle of $45^{\circ}$. No flake or chip, no whitening and no sound during scratching the sample indicated an excellent finishing property. The glossyness test was determined in accordance to SNI-06-6052-1999 (SNI 1999a adopted from ASTM D523 1970). The gloss of sample was measured with micro gloss device with an incidence angle $60^{\circ}$. The reflectance from the specimen was compared to that from a black glass standard. Gloss value of 100 represented a perfect condition of illumination. Delamination test was also conducted to meet Indonesian Standard of SNI 01-5008.2-1999 (SNI 1999b). This test measured the quality of bonding between nitrocellulose coating and surface of lumber that impregnated with PEG-1000. This test measured the resistance to delamination of coated sample under weathered condition. The coated samples were dipped in the water with temperature of $70^{\circ} \mathrm{C} \pm 3^{\circ} \mathrm{C}$ for 2 hours and then dried in the oven at temperature of $60^{\circ} \mathrm{C} \pm$ $3^{\circ} \mathrm{C}$ for 3 hours. Delaminated area was calculated as a percentage of the total area tested.

Analyses of variance with $\alpha=0.05$ were conducted to analyze significant difference of the ASE, drying, machining and finishing properties among five different concentrations. Tukey's Honestly Significant Different (HSD) was used to determine the test differences.

\section{Results and Discussion}

\section{Dimensional Stability}

Dimensional stability of young teak wood was improved by impregnation of PEG-1000 in various concentrations. Anti shrink efficiency of the samples that were impregnated by PEG-1000 are shown in Fig. 2. This result correspond to Mortensen et al. (2007) who stated that PEG with a molecular weight of 1000 , is easily dissolved in warm water and could be assimilated successfully into fine structures of porous materials through diffusion. In addition, susceptibility of the wood material to water is decreasing as reducing free $-\mathrm{OH}$ groups in wood (Mahlberg et al. 2001). There was significant difference $(P<0.05)$ on ASE among the samples that impregnated by PEG-1000 with five concentrations, in both radial and tangential directions. The ASE of the samples impregnated with PEG-1000 at concentration of $20 \%$ was the lowest compared to the other one. In contrast, no significant difference was found on ASE among the samples that were impregnated at concentration of $30 \%, 40 \%, 50 \%$, and $60 \%$. The ASE of samples that impregnated with concentration $30 \%$ to $60 \%$ varied from $54 \%$ to $62 \%$. This result met the minimum requirement of bulking process to improve successful dimensional stabilization, which is shown by ASE more than $50 \%$ (Mitchel 1971; Kollmann et al. 1975). This results is also concordance with the previous research that PEG-1000 is one of the non leachable chemicals, which could be impregnated into wood with ASE ranges between $50-80 \%$ (Rowell and Youngs 1981). The satisfied result of ASE is because of PEG-1000 ability to penetrate into the wood from wood cell lumens into adjacent cell walls (Jeremic et al. 2007). Therefore, it is recommended to impregnate young teak wood with PEG-1000 at minimum concentration of $30 \%$ to obtain ASE more than $50 \%$. 


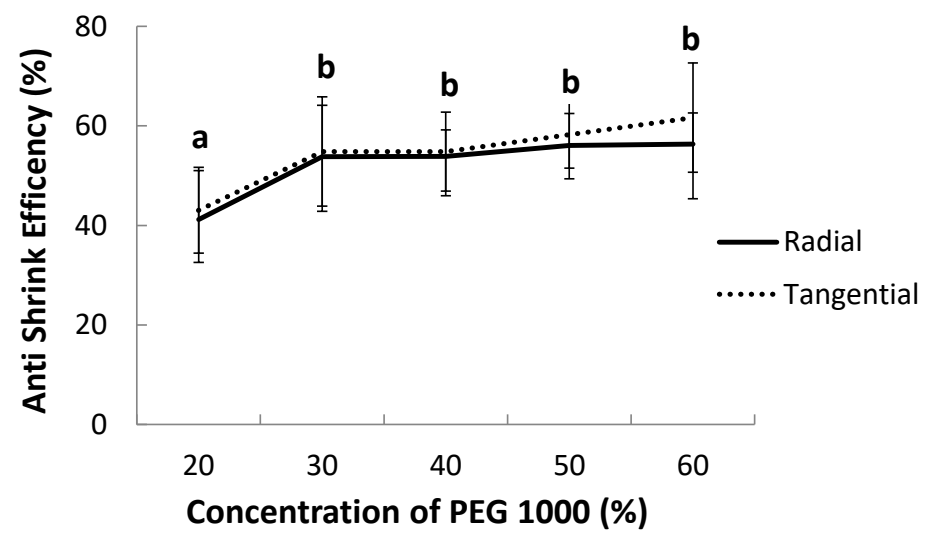

Fig. 2. Anti shrink efficiency of the samples that were impregnated by PEG-1000 in both radial and tangential direction. Note: Different alphabet $(a, b)$ above error bars indicate significant differences, based on Tukey HSD test.

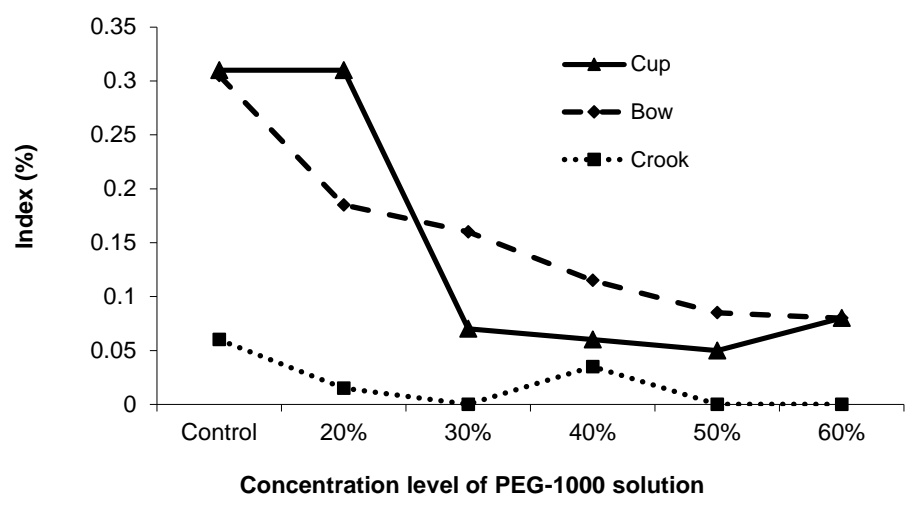

Fig. 3. Index (\%) of cupping, bowing and crooking after drying to moisture content of $12 \%$.

\section{Drying Characteristics}

Interestingly, there is no surface check in modified wood after drying in $12 \%$ moisture content. Surface checks were only found in control sample with the total length of 20 156 mm. There were significant difference $(P<0.05)$ in bowing, and cupping found among concentration level of PEG-1000 solutions. Index (\%) of cupping, bowing and crooking after drying to moisture content of $12 \%$ can be seen in Fig. 3. According to Tukey HSD test, the index value of warping of modified sample showed lower percentage than control (unmodified) one. However, there is no significant difference in warping among concentration of $20 \%, 30 \%, 40 \%, 50 \%$ and $60 \%$. This result indicated that modified sample has better quality compare to those of unmodified samples. Mitchel (1971) stated that getting enough PEG into the outer shell to provide protection during drying, which will be free of seasoning checks and splits.
This result is in line with previous study, that ASE improvement will lead to high dimensional stabilization without appreciable warping and checking (Ralph 2006). It means that increasing the concentration level of PEG1000 does not significantly affect the presence of warping. Subsequently, impregnation using 20-30\% PEG may be appropriate in relation to avoid warp defect.

\section{Machining Characteristics}

Machining test was conducted to investigate the behaviour of sample under wood working process after impregnating by PEG-1000. The machining properties of the sample impregnated with PEG-1000 in various concentrations are shown in Fig. 4. Statistical analysis showed that the defects areas of impregnated samples were significantly $(P<0.05)$ lower than that of control sample. It means that impregnation by PEG-1000 improved machining 


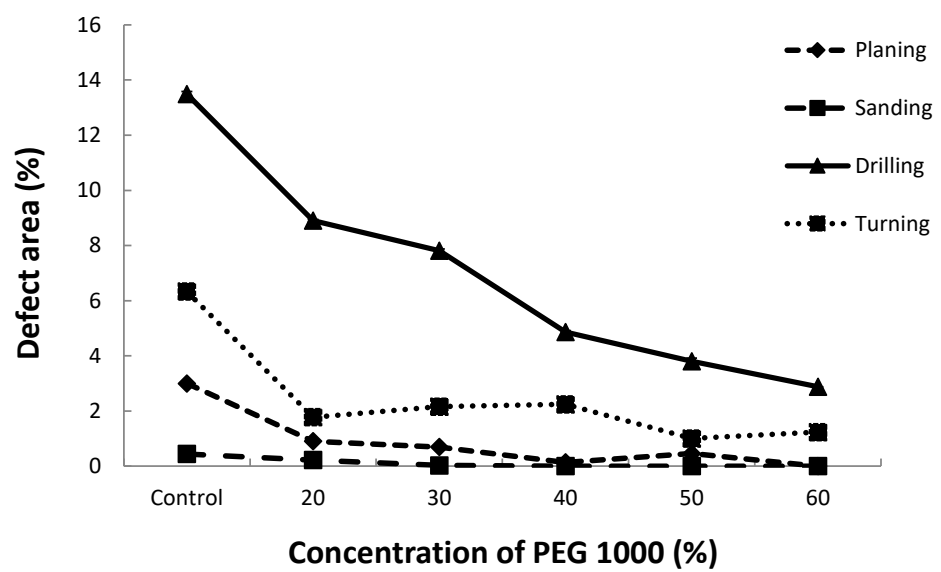

Fig. 4. Graph of machining properties of teakwood that impregnated with PEG-1000 at five concentration and also control sampel.

properties of young teak wood. Analysis of variance also showed that significant difference $(P<0.05)$ on machining properties was found among five concentrations of PEG1000. The amount of defects also decreased as PEG-1000 concentration improvement. Generally, all machining test caused defects of the impregnated samples less than $10 \%$, which was classified into Grade 1 (excellent) and Grade 2 (Good) based on ASTM D1666-87 (ASTM International 2004). This defect of samples under machining operation make the sample met the minimum requirement for furniture and handicraft, which should be less than $10 \%$.

\section{Finishing Characteristics}

High-quality of finishing process to the surface of samples were indicated by scratch resistance, which were revealed by cross-cut and coin tests. Cross-cut test showed that the amount of flakes separated from the sample surface was significantly different $(P<0.05)$ among impregnated sample. Impregnated samples with PEG-1000 at concentration level of $20 \%$ and $40 \%$ showed lower percentage of flaking areas than other samples (Fig. 5). Coin test was also confirmed that samples impregnated with PEG-1000 at concentration of 20 40\% produce an excellent and good response of scratching test (Fig. 6). This result should be related to the increase of dimensional stability of impregnated samples. Improving dimensional stability could reduce the amount of flakes of finished lumber (Williams 1999). However, it should be noted that increasing concentration of PEG-1000 also caused waxy surface of the sample in which finishing process could not work properly (Mitchel 1971). This reason explains on why the amount of flaking area of impregnated samples with concentration of $50 \%$ and $60 \%$ were high. To obtain low percentage of flaking areas, therefore, it is recommended to impregnate young teak wood with PEG-1000 at concentration of $20 \sim 40 \%$.

Considerably the resistance of nitrocellulose coating delamination was found on the sample impregnated with PEG-1000. The best result was a sample that impregnated with PEG-1000 at concentration of $20 \%$, which was no delamination area. Delaminated areas of impregnated samples with PEG-1000 at concentration of $30-60 \%$ were less than $1 \%$. Increasing concentration of PEG-1000 caused higher percentage of the delaminated area of the impregnated sample. This result is related to the sticky sawdust on the surface of samples due to sanding process before coating. It is important to note that sticky surface may cause a failure in high quality bond between finish and surface of lumber. Consequently, it is recommended to assure the proper roughness of the surface of impregnated sample by PEG-1000 to achieve high quality bound between finish and lumber. Mitchel (1971) suggested that the waxy sawdust could be reduced by sponging the surface with warm water and continued by $3 / 0$ and $6 / 0$ wet or dry sand paper.

There was no significant difference $(P>0.05)$ in gloss value among tested samples. The gloss of impregnated sample varied from $77 \%$ to $81 \%$, which was classified to medium gloss. The glossyness of impregnated samples was slightly lower than that of control samples, which was $82 \%$. Regarding carving and furniture from teakwood, rough and very glossy finishing are not recommended because the aesthetic properties of wood grain will not appear clearly. Subsequently, this level of gloss of impregnated samples remains sufficient as a high quality of furniture and carving products. 


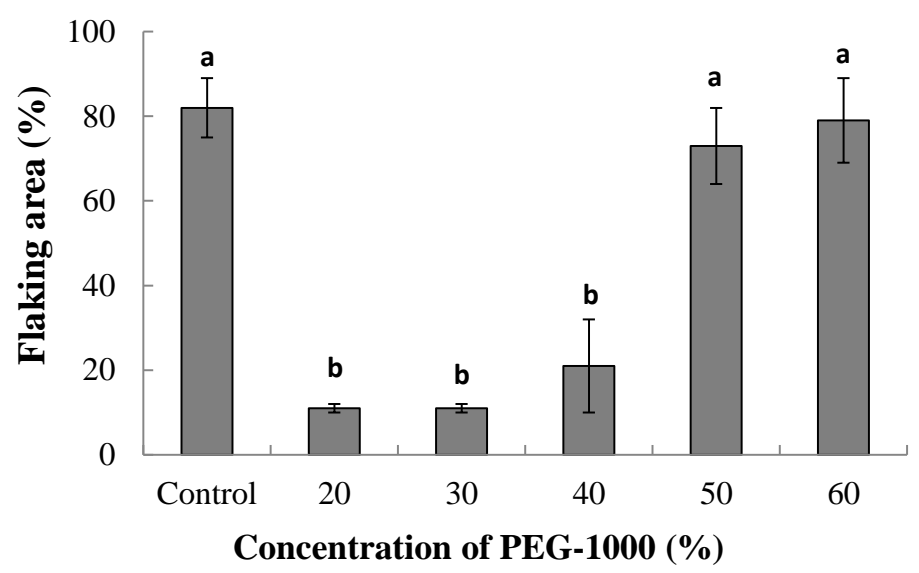

Fig. 5. Flaking area percentage of sample impregnated with PEG-1000 at five concentrations as a result of cross-cut test. Note: Different alphabet $(a, b)$ above error bars indicate significant differences, based on Tukey HSD test.

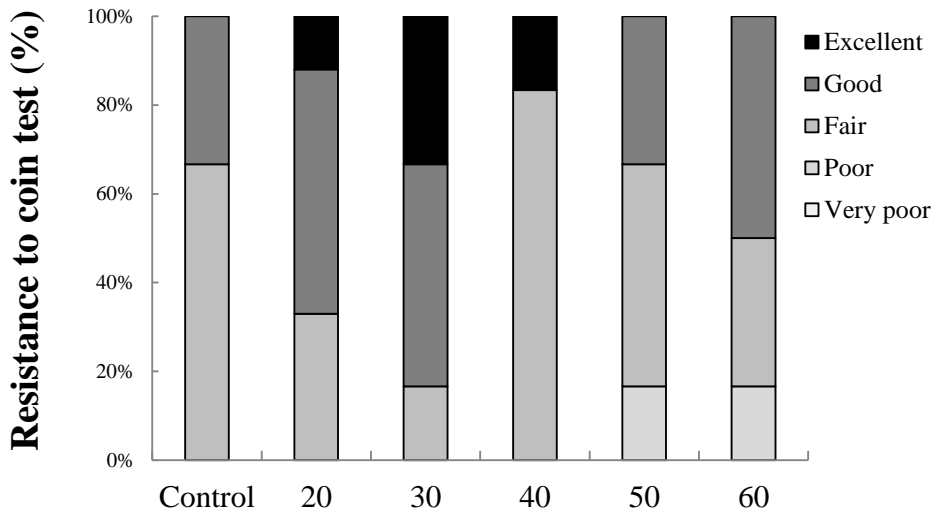

Concentration of PEG 1000 (\%)

Fig. 6. Resistance to coin test (\%) of sample impregnated with PEG-1000 at five concentrations

\section{Conclusions}

To obtain desired dimensional stability with requisite good performance in drying, machining and finishing characteristics, five concentrations of PEG-1000 were impregnate to young teak wood. The result shows that impregnation of PEG-1000 with concentration of 30 60\% improved the dimensional stability of young teakwood significantly, which was in the range between $52 \%$ and $62 \%$. The result indicates that the impregnation of PEG-1000 could enhance drying and machining characteristics, as shown by the area of defect-free, which was higher than $90 \%$. The impregnated teak wood also showed a good result on finishing properties. Considering the result of dimensional stability and characteristics of drying, machining and finishing properties, it is recommended to impregnate young teak wood with PEG-1000 at concentration of $30 \%$.

\section{Acknowledgements}

This research was supported by the Ministry of Education, Republic Indonesia. Part of this article has been presented in 21st International Wood Machining Seminar, 47 August 2013 in Tsukuba and 1st International Symposium of IWORS. 2-3 November in 2009 Bogor.

\section{References}

ASTM International. 2004a. ASTM D1666 - 87. Standard Methods for conducting Machining Tests of Wood and Wood-Base Materials. West Conshohocken, PA, USA: ASTM International.

ASTM International. 2004b. ASTM D3559. Standard Test Methods for Measuring Adhesion by Tape Test. . West Conshohocken, PA, USA: ASTM International. 
Avramidis, G.; G. Scholz; E. Nothnick; E. Militz; W. Viol; and A. Wolkenhauer. 2011. Improved Bondability of Waxtreated Wood following Plasma Treatment. Wood Science and Technology 45(2): 359-368.

Davis, E.M. 1962. Machining and Related Characteristics of United States Hardwoods. In. Technical Bulletin No. 1267, United States Department of Agriculture, Forest Service. p. 70.

Fadl, N.A. and A.H. Basta. 2005. Enhancement of the Dimensional Stability of Nature Wood by Impregnates. Pigment and Resin Technology 34(2): 72-86.

Hadikusumo, S.A. 2001. Sawing Pattern of Teakwood from the Community Forest and its Physical and Mechanical Properties. Forestry Bulletin 47: 1-14.

Hillis, W.E. 1984. High Temperature and Chemical Effects on Wood Stability. Wood Science and Technology 18(4): 281-293.

Ibach, R.E. 1999. Specialty Treatments. In, Wood Handbook: Wood as an Engineering Material. U.S. Department of Agriculture, Forest service, Forest Products laboratory, Wisconsin, p. 463.

Jeremic, D.; P. Cooper; D. Heyd. 2007. PEG Bulking of Wood Cell Walls as Affected by Moisture Content. Wood Science and Technology 41: 597-606.

Koch, P. 1964. Wood Machining Process. The Ronald Press Company, New York.

Kollmann, F.F.P.; E. W. Kuenzi; A. J. Stamm. 1975. Principle of Wood Science and Technology. SpringerVerlag, New York.

Mahlberg, R.; L. Paajanen; A. Nurmi; A. Kivisto; K. Koskela; R.M. Rowell. 2001. Effect of Chemical Modification of Wood on the Mechanical and Adhesion Properties of Wood Fiber/Polypropylene Fiber and Polypropylene/ Veneer Composites. Holz als Roh und Werkstoff 59: 319-326.

Mitchel, H.L., 1971. How PEG Helps the Hobbyist Who Work with Wood. In. United State Department of Agriculture, Forest Service, Forest Products Laboratory.

Mitchell, H.L., and H.E. Wahlgren. 1959. New Chemical Treatment Curbs Shrink and Swell of Walnut Gunstocks. Forest Products Journal 9(12): 437-441.

Mortensen, M.N.; H. Egsgaard; S. Hvilsted; Y. Shashoua; and J. Glastrup. 2007. Characterization of the Polyethylene Glycol Impregnation of the Swedish Warship Vasa and One of the Danish Skuldelev Viking ships, Journal of Archaeological Science 34(8): 12111218.

Pandey, D. and C. Brown. 2000. Teak: A Global Review. Unasylva 201 51: 3-13.
Panshin, A.J. and C. de Zeeuw. 1980. Text Book of Wood Technology. McGraw-Hill Book Company, New York.

Ralph, J. 2006. PEG Penetration and the Effects of PEG Pretreatment in Air-dried Eucalyptus regnans. Wood and Fiber Science 38(1): 139-143.

Richter, K.; W.C. Feist; and M.T. and Knaebe. 1995. The Effect of Surface Roughness on the Performance of Finishes. Part 1: Roughness Characterization and Stain Performance. Forest Product Journal 45: 91-97.

Rowell, R.M. and R.L. Youngs. 1981. Dimensional Stabilization of Wood in Use. In. Forest Products Laboratory, United States Department of Agriculture, Winconsin.

Sangkul, S. 1998. Processing and Development Technology and Future Trends for Teak Utilization. In: M, K., K, W. (Eds.), The Second Regional Conference on Teak. FAO, pp. 123-130.

Schneider, M.H. 1994. Wood Polymer Composites. Wood and Fiber Science 26(1): 142-151.

Stamm A.J. 1959 Effect of Polyethylene Glycol Treatment Upon Dimensional Stabilization and Other Properties of Wood. For Prod J 9: 375-381

Standard National Indonesia (SNI). 1999a. SNI 06 - 6052 1999, Gloss Test Procedure (Cara Uji Kilap Jadi). Badan Standarisasi Indonesia - BSN. Jakarta.

Standard National Indonesia (SNI). 1999b. SNI 01-5008.21999. Plywood and Block Board for General Purposes (Kayu Lapis dan Papan Blok Penggunaan Umum). Badan Standarisasi Indonesia - BSN. Jakarta.

Walker, J.C.F. 2006. Primary Wood Processing: Principles and Practice. Chapman \& Hall, London.

Wallstrom, L. and K.A.H. Lindberg. 1995. Wood Surface Stabilization with Polyethylene Glycol. Wood Science and Technology 29: 109-119.

Williams, R.S. 1999. Finishing of Wood. In, Wood Handbook: Wood as an Engineering Material. Forest Products Laboratory, USDA Forest Service, Wisconsin.

Tomy Listyanto and Muhammad Navis Rofii

Universitas Gadjah Mada, Yogyakarta, Jl. Agro No.1, Bulaksumur, Yogyakarta, INDONESIA

Tel. : : +628157950924

Fax. : : +62274550541

E-mail : tomy.listyanto@gadjahmada.edu

Keisuke Ando, and Nobuaki Hattori

Tokyo University of Agriculture and Technology, 3-5-8

Saiwai-cho, Tokyo, JAPAN 